\title{
Detection of Toxoplasma gondii from Native Cattle in Southwest of Iran
}

\author{
Asghar Arshi, Esmaeil Mahmoudi, Mohammad-Saeid Jami, Abbas Doosti*
}

Biotechnology Research Center, Islamic Azad University, Shahrekord Branch, Shahrekord, Iran

\section{Email address:}

asghararshi@yahoo.com (A. Arshi), esmailmahmoodi72@gmail.com (E. Mahmoudi), sjamimail@yahoo.com (M. S. Jami), bioshk@yahoo.com (A. Doosti)

\section{To cite this article:}

Asghar Arshi, Esmaeil Mahmoudi, Mohammad-Saeid Jami, Abbas Doost. Detection of Toxoplasma gondii from Native Cattle in Southwest of Iran. Animal and Veterinary Sciences. Vol. 3, No. 4, 2015, pp. 102-105. doi: 10.11648/j.avs.20150304.11

\begin{abstract}
Infections by protozoan parasite Toxoplasma gondii are prevalent worldwide in animals and human. T. gondii is the causative agent of toxoplasmosis, one of the most prevalent parasitic infections to humans and domestic animals. If first be during pregnancy, $T$. gondii may be transferred vertically by tachyzoites that are passed to the embryo via the placenta. $T$. gondii may be transmitted horizontally in three phases of the life cycle, ingesting infectious oocysts from the environment or tissue cysts or tachyzoites which are contained in gastrointestinal of many different animals. Transmission may also occur via tachyzoites contained in blood products, texture transplants or non-pasteurized milk. Like rest of the world toxoplasmosis is prevalent in Iran. The present study aimed to determine T. gondii isolates from native cattle in Chaharmahal Va Bakhtiari province located in south west of Iran by molecular methods. In this study, 155 blood samples were collected from native cattle. Genomic DNA was extracted using DNA extraction Kit (Cinna Gen, Iran) according to the manufacturer protocol and PCR was performed using specific primers (ITS-F and ITS-R). Sixteen (6.95\%) cattle were positive to T. gondii infection. The positive control samples showed the excepted amplification product specific for $T$. gondii (171 bp). Although the present results showed relatively low prevalence of T.gondii infection in Chaharmahal Va Bakhtiari native cattle, control and eradication programs seem to be still necessary to prevent the prevalence of this infection factor and economic losses.
\end{abstract}

Keywords: Toxoplasma gondii, Toxoplasmosis, Native Cattle, PCR, Iran

\section{Introduction}

Toxoplasma gondii (T. gondii) is a protozoan parasite mandatory which infects all warm-blooded animals such as marine, mammals, humans, animals and birds [1]. This obligate intracellular protozoa was identified in 1908 in a North African rodent. Its intermediate hosts could be humans or other warm-blooded animals [2]. T. gondii infection causes mental retardation, loss of vision and other congenital health problems in human newborns [3]. The world prevalence of Toxoplasmosis in human is about 10-30\% [4]. In other words up to one-third of the world populations suffer from Toxoplasmosis, an infection caused by $T$. gondii $[5,6]$. This parasite belongs to apicomplexa, the phylum which also includes main human and domestic animal's pathogens such as Plasmodium (causative agent of malaria), Cryptosporidium (diarrhea), Eimeria (coccidiosis in poultry) and Theileria (East Coast Fever in cattle) [7]. While the infection is asymptomatic in persons with healthy immune system it can be fatal in immune compromised people. Infection during pregnancy can result in feeble offspring, abortion and stillbirth, or birth defects. Moreover, ocular diseases have been reported as toxoplasmosis outcome, that can sometimes be severe in adults resulting in loss of vision and cognitive function and even fatal encephalitis $[8,9]$. There are three infectious stages of $T$. gondii sporozoites (in oocysts), slow growing bradyzoites (in tissue cysts) and rapidly dividing tachyzoites (in pseudocysts) which can be transmitted through two main routes (sexual and asexual) [8]. The sexual period of the parasite only occurs in the intestine of the definitive host (domestic and wild cat), and results in the excretion of oocytes in stool [10]. Generally $T$. gondii is transmitted through ingestion of partly cooked meat, pork or lamb containing Toxoplasma cysts or unwashed fruits or vegetables that have been in contact with contaminated soil containing infected cat feces [11]. Together with atypical and recombinant species three important clonal lineages of $T$. gondii, specified as Type I, II and III, have been classified according to their genetic multiform. It has been shown that 
type I and some of the recombinant or atypical species are virulent in mice, whilst genotype II and III are non-virulent [12].

Over the past decade, the use of Polymerase Chain Reaction (PCR) assay has had significant advances for toxoplasmosis detection both in congenital diseases (before birth) and acute toxoplasmosis in immune compromised patients. Among the PCR-based assays, nested-PCR followed by hybridization has been reported as the most sensitive detection technique for the detection of toxoplasmosis [13].

Internal transcribed spacer (ITS) is a fragment of nonfunctional RNA situated among structural ribosomal RNAs (rRNA) [14]. Read from 5' to 3', the polycistronic rRNA transcript has the $5^{\prime}$ ETS ( $5^{\prime}$ external transcribed sequence), 18S rRNA, ITS1, 5.8S rRNA, ITS2, 28S rRNA and the 3' ETS. Since ITSs are easy to amplify even from small quantities of DNA (due to the high copy number of rRNA genes), and they have a high degree of variation even between closely related species, the sequence comparison of the ITS region is widely used in taxonomy and molecular phylogeny [15]. In this work we aimed to investigate the prevalence of $T$. gondii from Iranian native cattle by molecular studies on ITS-1.

\section{Materials and Methods}

\subsection{Samples Collection}

One hundred fifty five (155) native cattle blood samples were collected from slaughterhouse in Chaharmahal Va Bakhtiari province and transferred into a sterile tube and stored in 0.05 M EDTA. For ethical approval in this study the protocol and informed consent forms were approved by the Islamic Azad University, Shahrekord Branch, Shahrekord, Iran with 17621105 grant number. Genomic DNA from specimens was extracted using DNA Extraction Kit (Cinna Gen, Iran) according to the manufacturer's protocol. The extracted DNA was quantified by spectrophotometric measurement at a wavelength of $260 \mathrm{~nm}$. The extracted DNA of each specimen was kept frozen at $-20^{\circ} \mathrm{C}$ until used.

\subsection{Gene Amplification}

Specific primers for ITS-1 of $T$. gondii were used for gene amplification. Forward primer begins at base 97 with the following sequence Toxo-F: 5'CATTGGAGAGATTTGCATTC -3' and reverse primer begins at base 240 with the sequence Toxo-R: 5'ATCAGTATCCCAACAGAGACAC -3', therefore a fragment of 171 base pairs was expected. PCR test was performed in final volume of $25 \mu \mathrm{l} \mathrm{PCR}$ reactions containing $100 \mathrm{ng}$ of template DNA, $1.5 \mathrm{mM} \mathrm{MgCl} 2,200 \mu \mathrm{M}$ dNTPS, $2 \mathrm{mM}$ of each primers and one unit of Taq DNA polymerase enzyme. Thermal PCR conditions consisted of initial $5 \mathrm{~min}$ at $95^{\circ} \mathrm{C}$ and then 32 cycles of denaturing temperature at $94^{\circ} \mathrm{C}$ for 1 min, annealing temperature at $56^{\circ} \mathrm{C}$ for $1 \mathrm{~min}$, extension at $72^{\circ} \mathrm{C}$ for $1 \mathrm{~min}$, and final extension at $72^{\circ} \mathrm{C}$ for $5 \mathrm{~min}$.
The amplification products were analyzed by $1.5 \%$ agarose gel electrophoresis. Electrode buffer was TBE (Tris-base $10.8 \mathrm{~g}, 89 \mathrm{mM}$, boric acid $5.5 \mathrm{~g}, 2 \mathrm{mM}$ EDTA (pH 8.0) $4 \mathrm{ml}$ of 0.5 MEDTA ( $\mathrm{pH}$ 8.0), with all components joined in enough $\mathrm{H}_{2} \mathrm{O}$ and stired to dissolve). Gels were stained with ethidium bromide, aliquots of $10 \mu \mathrm{l}$ of PCR products were applied to the gel. Constant voltage of $80 \mathrm{~V}$ for $30 \mathrm{~min}$ was used for products separation. After electrophoresis, generated bands were screened and digitally photographed under UV light.

\subsection{Statistical Analyses}

Data were analyzed by the chi-square test using the SPSS 17 (SPSS Inc. Chicago, IL, USA) software. P values $<0.05$ were considered significant.

\section{Results}

Agarose gel electrophoresis of positive samples revealed a $171 \mathrm{bp}$ fragment. An example of PCR amplification of blood samples is shown in Figure 1. From 155 samples collected, $T$. gondii DNA was detected in 16 cattle blood samples in this study. Our results showed a low frequency $(6.95 \%)$ of $T$. gondii isolate in native cattle in Chaharmahal Va Bakhtiari province.

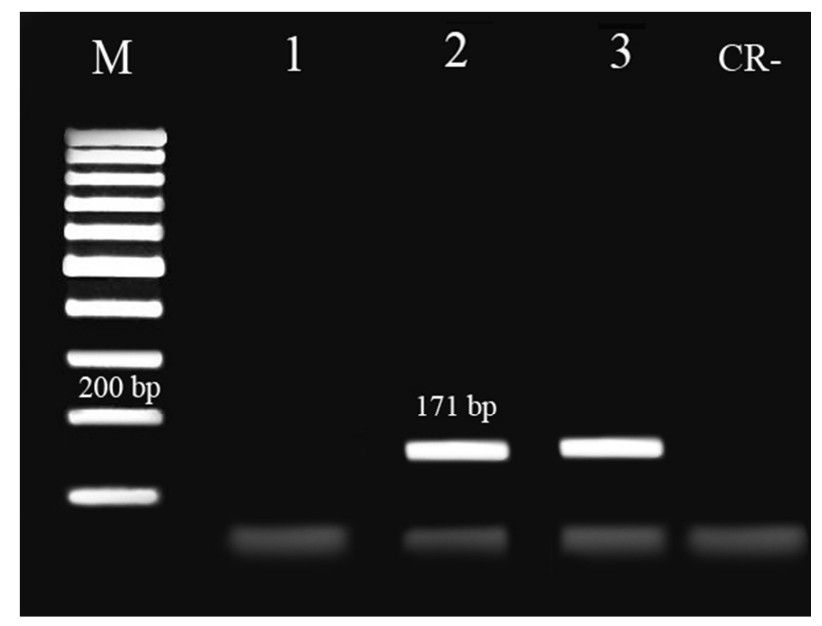

Figure 1. Gel electrophoresis for detection of T.gondii infection in blood samples. Lane M is 100 bp DNA ladder (Fermentas, Germany); lane 1 is a negative sample, lane 2 and 3 are positive samples, CR-is negative control.

\section{Discussion}

Toxoplasmosis is a zoonotic disease caused by $T$. gondii and has been known in many countries since 1908. T. gondii infection in cattle is distributed world-wide. There are multitude reports on comparison of different techniques on diagnosis of Toxoplasma infection [16]. PCR used to detect $T$. gondii is very efficient in rapid diagnosis of toxoplasmosis [17]. PCR technique, by which a part of $T$. gondii genome DNA is detectable with high sensitivity and specificity, is preferred to other techniques such as serological tests with variable sensitivity and specificity [18]. Blood samples are 
the most available sample required to perform PCR for diagnosis proposes in animals, birds and human cases [17]. In a human study Mohammed Yesuf et al. indicated that the prevalence of toxoplasmosis for HIV $\backslash$ AIDS patients in the Ethiopia was $60 \%$. The analysis shows that some health, economic and risk behavior factors influence exposure of patients to toxoplasmosis [19].

In this work we observed a low frequency $(6.95 \%)$ of native cattle population infected by $T$. gondii in Chaharmahal Va Bakhtiari province in Iran. Some similar studies in different regions of Iran showed the prevalence rate of $T$. gondii up to $15.9 \%$ in North-West of Iran [20], 21.6\% in coastal region of Caspian Sea [21], 32\% in Khuzestan province [22], and $13.8 \%$ in Ahvaz city [23].

Comparison of our results with other reports shows that the occurrence of toxoplasmosis varies between countries, influenced by traditions, customs and the life styles of the population. For instances studies have shown the infection rate of $7.8 \%$ in France [24], $15.7 \%$ in Spain [25], 76.3\% in Serbia [26], 5\% in north America [27] and 10.5\% in Vietnam [28].

In a study in Brazil, the number of $T$. gondii infected animals from farms that had a history of abortion or stillbirth was much higher than in animals from farms without abortion history $(\mathrm{P}=0.019)$ [29].

Age seems to be another important factor in toxoplasmosis. It has been reported that younger animals are more likely to become infected than other age groups e.g. cattle under the age of one year were significantly $(\mathrm{P}>0.05)$ more infected than the older cattle $[23,30]$.

\section{Conclusion}

The results of the present study showed that PCR, as a highly sensitive and specific method can be used for diagnosis, identification and differentiation of $T$. gondii and laboratory support is an important tool in disease diagnosis. Thus, it is essential to screen all regions regularly to prevent the spread of the disease. Although we showed a comparatively low prevalence of $T$. gondii in Iranian cattle, the control and eradication programs still seem to be necessary to prevent and reduce its negative effects on health and economy.

\section{Acknowledgments}

The authors would like to express their deep sense of gratitude and sincere thanks to the staff of the Biotechnology Research Center of Islamic Azad University of Shahrekord branch in southwest Iran.

\section{References}

[1] Holec-Gąsior, L., Drapała, D., Dominiak-Górski, B. and Kur, J. (2013). Epidemiological study of Toxoplasma gondii infection among cattle in Northern Poland. Ann. Agric. Environ. Med, 20(4): 653-656.
[2] Haeri, M.R., Jalalizadegan, B., Tabatabaie, F. (2014). Recognition of Acute Toxoplasmosis with IgG Avidity ELISA Test in the Pregnant Women (The First Trimester) in Qom Province, Iran, during Two Years (2012-2013). A. J. L. S, 2(63): $18-21$.

[3] Dubey, J.P., Rajendran, C., Ferreira, L.R., Martins, J., Kwok, O.C., Hill, D.E., Villena, I., Zhou, H., Su, C. and Jones, J.L. (2011). High prevalence and genotypes of Toxoplasma gondii isolated from goats, from a retail meat store, destined for human consumption in the USA. Int. J. Parasitology, 41(8): 827-833.

[4] Lopes, W.D., Rodriguez, J.D., Souza, F.A., dos Santos, T.R., dos Santos, R.S., Rosanese, W.M., Lopes, W.R., Sakamoto, C.A. and da Costa, A.J. (2013). Sexual transmission of Toxoplasma gondii in sheep. Vet Parasitol, 195(1-2): 47-56.

[5] Okada, T., Marmansari, D., Li, Z.M., Adilbish, A., Canko, S., Ueno, A., Shono, H., Furuoka, H. and Igarashi, M. (2013). A novel dense granule protein, GRA22, is involved in regulating parasite egress in Toxoplasma gondii. Mol Biochem Parasitol, 189(1-2): 5-13.

[6] Choi, K.M., Gang, J. and Yun, J. (2008). Anti-Toxoplasma gondii RH strain activity of herbal extracts used in traditional medicine. Int. J. Antimicrob Agents, 32(4): 360-362.

[7] Pratt, S., Wansadhipathi-Kannangara, N.K., Bruce, C.R., Mina, J.G., Shams-Eldin, H., Casas, J., Hanada, K., Schwarz, R.T., Sonda, S. and Denny, P.W. (2013). Sphingolipid synthesis and scavenging in the intracellular apicomplexan parasite, Toxoplasma gondii. Mol Biochem Parasitol, 187(1): 43-51.

[8] Grigg, M.E. and Sundar, N. (2009). Sexual recombination punctuated by outbreaks and clonal expansions predicts Toxoplasma gondii population genetics. Int .J. Parasitol, 39(8): 925-933.

[9] Masatani, T., Matsuo, T., Tanaka, T., Terkawi, M.A., Lee, E.G., Goo, Y.K., Aboge, G.O., Yamagishi, J., Hayashi, K., Kameyama, K., Cao, S., Nishikawa, Y. and Xuan, X. (2013). TgGRA23, a novel Toxoplasma gondii dense granule protein associated with the parasitophorous vacuole membrane and intravacuolar network. Parasitol Int, 62(4): 372-379.

[10] Miller, C.M., Boulter, N.R., Ikin, R.J. and Smith, N.C. (2009). The immunobiology of the innate response to Toxoplasma gondii. Int. J. Parasitol, 39(1): 23-39.

[11] Qu, D., Han, J. and Du, A. (2013). Enhancement of protective immune response to recombinant Toxoplasma gondii ROP18 antigen by ginsenoside Re. Exp Parasitol, 135(2): 234-239.

[12] Döşkaya, M., Caner, A., Ajzenberg D., Değirmenci, A., Dardé, M.L., Can, H., Erdoğan, D.D., Korkmaz, M., Uner, A., Güngör, C., Altıntaş, K. and Gürüz, Y. (2013). Isolation of Toxoplasma gondii strains similar to Africa 1 genotype in Turkey. Parasitol Int, 62(5): 471-474.

[13] Fallahi, S.h., Kazemi, B., Seyyed Tabaei, S.J., Bandehpour, M., Lasjerdi, Z., Taghipour, N., Zebardast, N., Nikmanesh, B., Omrani, V.F. and Ebrahimzadeh, F. (2014). Comparison of the $\mathrm{RE}$ and $\mathrm{B} 1$ gene for detection of Toxoplasma gondii infection in children with cancer. Parasitol Int, 63(1): 37-41.

[14] Rajaratnam, S. and Thiagarajan, T. (2012). Molecular characterization of wild mushroom. J. Exp. Bio, 2 (2): 369373 . 
[15] Kent, T., Lapik, Y.R. and Pestov, D.G. (2009). The 5' external transcribed spacer in mouse ribosomal RNA contains two cleavage sites. RNA, 15(1): 114-120.

[16] Sevinsc, F. (2000). The seroprevalence of Toxoplasma gondii in goats detected by indirect hemagglutination (IHA) and indirect florescent antibody (IFA) tests in the region of Konya. Acta Parasitologica Turnica, 24(1): 57-80.

[17] Tavassoli, M., Ghorbanzadehghan, M. and Esmaeilnejad, B. (2013). Detection of Toxoplasma gondii in sheep and goats blood samples by PCR-RFLP in Urmia. Vet. Res. Forum, 4: 43-47.

[18] James, G.S., Sintchenko, V.G., Dickeson, D.J. and Gilbert, G.L. (1996). Comparison of cell culture, mouse inoculation, and PCR for detection of Toxoplasma gondii: effects of storage conditions on sensitivity. J. Clin. Microbiol, 34: 15721575 .

[19] Mohammed Yesuf, K., Melese, Z.T. (2015). Prevalence of Toxoplasmosis in HIV/AIDS Patients in Mettu Karl Hospital. A. J. H. R, 3(3): 183-188.

[20] Ghazaei, C. (2006). Serological survey of antibodies to Toxoplasma gondii. Afr J Health Sci, 13(1-2): 131-4.

[21] Sharif, M., Gholami, Sh., Ziaei, H., Daryani, A., Laktarashi, B., Ziapour, S.P., Rafiei, A. and Vahedi, M. (2007). Seroprevalence of Toxoplasma gondii in cattle, sheep and goats slaughtered for food in Mazandaran province, Iran during. Vet. J, 174(2): 422-424.

[22] Nematollahi, A. and Moghadam, G. (2008). Survey on seroprevalence of anti-Toxoplasma gondii antibodies in cattle in Tabriz, Iran by IFAT. American. J. Anim. Vet. Sci, 3(1): 4042 .
[23] Raeghi, S., Akbarei, A. and Sadeghi, S. (2011). Seroprevalence of Toxoplasma gondii in sheep, cattle and horses in Urmia North-West of Iran. Iranian. J. Parasitol, 6(4): 90-94.

[24] Gilot-Fromont, E., Aubert, D., Belkilani, S., Hermitte, P., Gibout, O., Geers, R. and Villena, I. (2009). Villena, Landscape, herd management and within herd seroprevalence of Toxoplasma gondii in beef cattle herds from champagneArdenne, France. Vet Parasitol, 161: 36-40.

[25] González-Warleta, M., Castro-Hermida, J.A., Carro-Corral, C., Cortizo-Mella, J. and Mezo, M. (2008). Epidemiology of neosporosis in dairy cattle in Galicia (NW Spain). Parasitol Res 102(2): 243-249.

[26] Klun, I., Djurković-Djaković, O., Katić-Radivojević, S. and Nikolić, A. (2006). Cross-sectional survey on Toxoplasma gondii infection in cattle, sheep and pigs in Serbia: seroprevalence and risk factors. Vet Parasitol, 135(2): 121-131.

[27] Dubey, J.P. (1992). Isolation of Toxoplasma gondii from a naturally infected beef cow. J Parasitol, 78(1): 151-153.

[28] Huong, L.T., Ljungström, B.L., Uggla, A. and Björkman, C. (1998). Prevalence of antibodies to Neospora caninum and Toxoplasma gondii in cattle and water buffaloes in southern Vietnam. Vet Parasitol, 75(1): 53-57

[29] Fajardo, H.V., D'ávila, S., Bastos, R.R., Cyrino, C.D., de Lima Detoni, M., Garcia, J.L., das Neves, L.B., Nicolau, J.L. and Amendoeira, M.R. (2013). Seroprevalence and risk factors of toxoplasmosis in cattle from extensive and semi-intensive rearing systems at Zona da Mata, Minas Gerais state, Southern Brazil. Parasit Vectors, 6, 191.

[30] Dubey, J.P. (2009). Toxoplasmosis in sheep--the last 20 years. Vet Parasitol, 163(1-2): 1-14. 